\title{
Developing sustainable societies - a dialogical network perspective
}

\author{
Are S. Ingulfsvann, Ove Jakobsen and Øystein Nystad \\ Ecological Economics, University of Nordland, Bodø, Norway
}

\begin{abstract}
Purpose - The purpose of this paper is to describe and discuss how and to what extent creative dialogue processes can have an impact on regional political planning processes in Norway. Politicians at Nordland County invited representatives from six different regions in Nordland to participate in café dialogues.

Design/methodology/approach - The empirical material is collected from café-dialogues in Northern Norway in which representatives from civil society, business organizations, local government, and NGOs participated. The data processing is based on triangulation of hermeneutic interpretation, frequencies, and factor analysis.

Findings - The findings indicate that most people want a "greener" future; this can be described as sustainable societies based on ecological production, distribution, consumption, and redistribution. People take on a more radical position in their ideas about the future than most politicians. The factor analysis grouped the participants into the following categories; "Ecological economics", "Small is beautiful", "Entrepreneurs", and "Growth and control". A large number of the participants are categorized either as "Circulation economics" or "Small is beautiful".

Practical implications - To solve the challenges of modern society politicians can instigate more radical solutions than they are in the habit of doing. The participants in the café dialogues describe fundamental changes in order to attain viable local societies per 2030.

Originality/value - In this paper the authors demonstrate that cultural creatives in the USA give a relevant context for interpreting attitudes to change in small societies in Northern Norway.
\end{abstract}

Keywords Culture, Social economy, Environmental economics, Sustainable development, Well-being Paper type Research paper

\section{Introduction}

In this paper we describe and discuss how and to what extent creative dialogue processes can have an impact on regional political planning processes in Norway. Politicians at Nordland County invited representatives from six different regions in Nordland to participate in café dialogues. The project was a cooperation between Nordland County and Centre for Ecological Economics and Ethics at University of Nordland. The Regional Plan Strategy for Nordland County (2012-2016) indicates that; "the main driving forces in society today are globalization, knowledge/technology, climate/environment, and demographics" (p. 4). In addition, trends such as centralization, increased mobility, and dramatic changes in demography and economy affect Nordland. In other words, the politicians wanted to gain knowledge relevant for coping with some of the main challenges we face today. The time we are at present living in can, on the one hand, be described by; "amazing scientific

(C) Are S. Ingulfsvann, Ove Jakobsen and Øystein Nystad. Published by Emerald Group Publishing Limited. This article is published under the Creative Commons Attribution (CC BY 3.0) licence. Anyone may reproduce, distribute, translate and create derivative works of this article (for both commercial \& non-commercial purposes), subject to full attribution to the original publication and authors. The full terms of this licence may be seen at http://creativecommons.org/ licences/by/3.0/legalcode
Developing

sustainable

societies

583

Received 29 August 2013

Revised 28 March 2014

8 April 2014

Accepted 10 June 2014

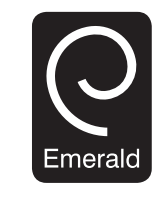

International Journal of Social Economics

Vol. 42 No. 6,2015 pp. $583-596$ Emerald Group Publishing Limited DOI 10.1108/IJSE-08-2013-0193 
IJSE

42,6

584

discoveries, technological inventions, industrial and commercial expansion, population increase, social transformations, new systems of transportation and communication, vast educational and research establishments, ventures into space” (Berry, 2007a, p. 57). On the other hand, there is another much more negative scenario:

Mountains are ripped apart for the underlying coal and ore deposits; rivers are polluted with human and industrial waste, the air is saturated with toxic substances, the rain is turned to acid, the soil is sterile with chemicals, the higher forms of life is endangered, the great mammals have been killed off almost to the point of extinction, the tropical forests are being ruined, and many coral reefs are dangered beyond repair (Berry, 2007a, p. 57).

According to Max-Neef we face a crisis of humanity, since it seems, for the first time in human history, that several "crises converge to simultaneously reach their maximum level of tension" (Max-Neef, 2010, p. 201). The more degraded ecosystems become, the greater the risk is that these systems will be pushed over the edge. Through the café dialogues the politicians wanted to confront the population in the region with the environmental challenges and listen to their reflections on how we can cope with them at a regional level.

According to Zsolnai the environmental challenges are closely connected to the economy and he argues that business affects the ecosystems at different levels; "Individual biological creatures are affected by business via hunting, fishing, agriculture, animal testing, etc. Natural ecosystems are affected by business via mining, regulating rivers, building, polluting the air, water and land, etc. The Earth as a whole is affected by business via exterminating species, contributing to climate change, etc." (Zsolnai, 2011, p. 893). Hence; the politicians in Nordland need knowledge relevant for handling these interrelated challenges.

\section{Geographical context, research problem and structure}

Nordland County is situated in the northern part of Norway, covering an area of $3,846,036$ square kilometers and 240,527 inhabitants. Traditionally this part of Norway has, even though a quite remote location, been quite open. Fisheries and small-scale farming first constituted the main way of living, with industrialization taking place after Second World War. Tourism has become gradually more and more important, and today opportunities for oil extraction off the coast are in the planning process. An important choice with respect to the future is the difference between building sustainable societies for the future or using easy opportunities for quick economic growth based on an intensified use of natural resources in an unsustainable way.

The purpose of the café dialogues was to stimulate creative processes that could lead to innovative solutions to some of the most pressing challenges Nordland County faces concerning the interplay between the economy, nature, and society. The politician's rationale for participating in the project was first and foremost instrumental; they wanted input for their planning process related to the Regional Plan for Nordland (2013-2025).

As a context of interpretation for our study we have chosen Ray and Andersons' distinction between traditionals, moderns, and cultural creatives. We elaborate on whether people in Nordland want a fundamental change towards sustainable development, or if they give priority to continuing more or less in the same direction as earlier. A consequence of focusing on the future, is that we uncover and interpret visions and utopias found in the population, instead of describing historically based trends. Although the data collected through the cafe dialogues, in the different regions, does not provide a basis for extensive generalizations, the data does offer room for interpretations relevant as input in political planning processes. 
We have structured the paper in the following way; First, we present and reflect on the theoretical context of the study. Second, we explain the choice of methodology. Third, we present and interpret the empirical material. Lastly, we sum up and draw some conclusions relevant for the political planning process in Nordland County, and include how the results were used by the politicians.

\section{Theoretical reflections}

Neo-liberal economics describes the economic process as a self-sustaining circular flow between production and consumption. An economy "chugging away machine-like in an infinite universe assumes potentially unlimited growth" (Rees, 2007, p. 106). Today, both economists and politicians believe not only in the possibility of exponential economic growth, they even regard this as a necessity for a healthy economy. Neo-liberal economic theories are built on a mechanistic worldview, in which autonomous economic actors optimize their individual interest in a competitive market. Ims and Jakobsen (2008) argued that changes at system level are not sufficient; attitudes and values must be changed as well.

The annual increase in GNP is looked on as being the primary indicator of a healthy society. Ensnared in this mechanical economic cosmos, we draw increasingly on economic theory in order to explain reality and guide our choices. This is strange because one can safely assume that no one wants to be the one-dimensional economic man, as presupposed in neo-liberal economic theory. (Ingebrigtsen and Jakobsen, 2009). Most of us like to think of ourselves as multidimensional integrated human beings. "The history of the world economy has proved that nothing is so reliable as the triumph of the free market - over reason" (Lindner, 2012, p. xxix).

One serious problem is that economic theory is abstracted from physical reality, in other words the idea is that the economy is more real than reality. Whitehead called this problem the "fallacy of misplaced concreteness" (Whitehead, 1978). Rand expresses the same knowledge warning: "We can evade reality, but we cannot evade the consequences of evading reality" (Lindner, 2012, p. 58). The point is that in reality, economy is integrated in the natural and cultural environment and cannot be separated, without getting into serious trouble. In other words, it is hard to avoid unintended consequences if we fall into the fallacy of misplaced concreteness.

What we are facing is a challenge asking for a deep change in our understanding of the world we live in; in other words, we need a change both at ontological and epistemological level. Such a change requires a creative synthesis of, science, social sciences, and humanities. This implies a more comprehensive and integrated understanding of the world we live in. Humanity has the capacity either to destroy or assist the unfolding of the basic life processes. The transforming sequence is in the direction of; "an increasing differentiation, a deepening subjectivity, and a more comprehensive communion within the total order of the real" (Berry, 2007b, p. 77).

We face challenges in the efforts to turn our attitude and behaviour towards nature and society in a more realistic and responsible direction. The interaction between economic, ecological and social systems should be based on an organic worldview. Sustainability and well-being depend on the harmonic interplay between the three systems. According to Lindner, "We [...] live in historically unprecedented times of risk, but also in historically unprecedented times of opportunity" (Lindner, 2012, p. xxv).

The tension between the mechanical and the organic worldviews lead to certain challenges in development of a society. Interpreting our data, we find similarities with the categories; moderns, traditionals, and "cultural creatives", as described by Ray and
Developing sustainable societies 
IJSE

42,6

Anderson (2000). Lindner (2012) argues that deep change is propelled by the avantgarde ("cultural creative"). The majority ("moderns") is undecided, and there is a group which lags behind ("traditionals").

These groups represent different solutions to the development of a society, and the key to a sustainable development can be found in how the population sees their ideal future.

\section{Moderns, traditionals and cultural creatives}

Traditionals, leaning back on the good old days, were the first counterculture to defect from modernism. Cultural creatives, leaning forward towards a society based on new values and worldviews were founded in the 1970s. In times of environmental and economic crisis; "we need people of courage, people who step out of the beaten track of familiarity and look at the situation from a new perspective" (Lindner, 2012, p. 7). Cultural creatives bridge the gap between experience from history and visions for the future. They are also characterized by looking for new ways to connect the different parts in an atomized modern world. The development of cultural creatives can be interpreted as a reaction to the growing number of negative unintended consequences of modernism. In other words, "leaning forward means stepping outside the old story and discovering a new one" (Ray and Anderson, 2000, p. 92). The cultural creatives develop new integrated ways of living, looking to eliminate the environmental and social conflicts inherent in modern society.

Now, we will elaborate on these three different cultures, moderns, traditionals, and cultural creatives, focusing on worldviews. "A worldview is to humans as water is to fish. It's the water we swim in" (Ray and Anderson, 2000, p. 92). The worldview becomes visible when something disrupts it, or referring to Kuhn, when the amount of anomalies threaten the existing paradigm.

\section{Moderns}

According to Ray and Anderson, the moderns have roots in urbanism and industrialism. They are inspired from big-government liberalism and business conservatism and the triumph of the modern world is connected to liberation from authoritarian political and religious control. Today, modernism is the dominant culture in most parts of the world. We find elements from modernism in almost every political debate and mass media are deeply influenced by topics from the modernist agenda. The success of the modernist culture is characterized by an impressive set of technical inventions for solving problems important in most peoples' daily life. The development can best be described as a process of change:

From village fairs to global market economies, from peasant agriculture to industrial societies, from tiny villages to an urbanized world, from human- and animal- powered handicrafts to a hundred powerful new technologies, from feudalism to nation-states, from medieval guilds to large corporations (Ray and Anderson, 2000, p. 71).

The positive side of modernism is a general increase in welfare for most people, at least in the industrialized countries in the West. Even more important is the value of individual freedom. This freedom liberates people enabling them to follow their dreams and talents in their life projects. It is hard for moderns to even think about returning to a situation involving limits on equality concerning; ethnicity, gender, religion, or education. The freedom to speak, travel, and participate in political debates are values that most of us take for granted.

On the other hand, many (unintended) negative side effects of modernism also exist and these effects are growing in importance. In 1936, Merton warned against "unanticipated consequences of purposive social action" (Merton, 1936, p. 894), and he 
differentiated the consequences using the following categories: consequences to the actor; and consequences to other persons mediated through the social structure, the culture and the civilization (Merton, 1936, p. 895). According to Merton himself, we can, to a large extent, interpret the destructive aspects of the modern society as unintended consequences of a society not in harmony with natural and social conditions. The continuing ecological depletion may soon begin to stress both economic and social systems. "Almost all Modernism's great solutions seem to bring terrible problems in their wake" (Ray and Anderson, 2000, p. 75). Globalized competitive markets have changed the nature of work in many Western countries, leading to downsizing and wage-cutting. According to Ray and Anderson, the quality of life is declining for middle-class Americans; they have to work harder and longer to maintain a 1970 standard of living.

Individualism has changed towards egoism, inherent values are replaced by instrumental values and value pluralism is reduced to a monetary value scale (Taylor, 1991). According to Nelson, the market economy has soul-destroying effects; "Our economic theory tells us that the heart of our lives, our soul, our substance [...] is caught up in goods and services [...] we evaluate everything by how well it delivers goods and services. As a result, we squeeze out the larger meanings" (Ray and Anderson, 2000, p. 77).

\section{Traditionals}

Traditionals place their hopes in recovering the society that existed previously; this is a culture of memory. They doubt whether the big consumption party ever was a good idea. Everything was better in the good old days: things were cleaner, and there were more principles and less conflicts than there are today. They prefer living in smaller towns and in the countryside. They turn away from the modern world that they do not understand. They also disapprove of many of the freedoms of the modern society including, amongst other things, women's liberation, and sexual expressiveness. They long for a society with a steady moral compass and they try to convince the majority of society to comply with their own ideas.

According to Ray and Anderson, the strengths and weaknesses of the traditionals are two sides of the same coin:

"Its strengths lie in its enunciation of shared beliefs, principles, and values that can claim a divine sanction, its use of simple images that appeal to less educated people, and its nostalgic appeal to tradition" [...] its weaknesses are an ethnic and racial politics that, with nostalgia and scapegoating, lends itself to authoritarianism, [...] which can make the complex realities of today's world even harder to deal with (Ray and Anderson, 2000, p. 81).

The traditionals can be designated the losers of the game of modernism; they chose to ignore the possibilities arising from new ideas and freedom.

They are usually people with less education than the regular middle class. Modernists accuse traditionals of being old-fashioned and inefficient.

\section{Cultural creatives}

Ray and Anderson argue that a deep changing process is already underway. Their arguments follow Eisenstein who points out that; "The present convergence of crises - in money, energy, education, health, water, soil, climate, politics, the environment, and more - is a birth crisis, expelling us from the old world into a new" (Eisenstein, 2011, p. xx).

A group of people named "cultural creatives", who have changed their substrate of values, may individually be "reshaping it in our culture as well" (Ray and Anderson, 2000,
Developing sustainable societies 
IJSE

42,6

588

p. 7). They combine content perspectives (unity in diversity) and process perspectives (subsidiarity). When cultural creatives change their values, a transformation of worldview never lies far behind. Ray and Anderson define worldview as "the content of everything you believe is real - God, the economy, technology, the planet, how things work, how you should work and play, your relationship with your beloved - and everything of value" (Ray and Anderson, 2000, p. 17).

It is interesting to notice that the cultural creatives deplore specialized abstract science, instead they are characterized by an intimate, engaged learning process imbued with the richness of direct experience. "It means opening spaces for dialogue and enhancing human dignity and equality" (Lindner, 2012, p. 5). They are convinced that "if they are not engaged, their convictions are just talk" (Ray and Anderson, 2000, p. 10). The cultural creatives focus on the patterns of interconnectedness between parts in whole systems. They move away from the dichotomy between individual and society and instead try to integrate the evolution of the self and the work of the whole. Therefore they are concerned about the condition of the planet and the well-being of people. One of the strengths of the cultural creatives is that they have green values and a positive vision of the future and that they try to implement this vision in the real world.

Ray and Anderson identified two wings of cultural creatives who differ in their values and beliefs, "those who turn their attention inward to gain new levels of consciousness and those who turn it outward as activists need to transcend their former mutual antagonism" (Lindner, 2012, p. 134). Half of the cultural creatives are more educated people in many different branches of the society. The other half is made up of the green cultural creatives with values centered on the environment, relationships, and social issues. They often support movements such as the ecology movement, feminism, alternative health care, self-actualization psychology, and spirituality with psychological focus. In leadership philosophy; "Deeper understanding of the interaction between prosperity, quality of life and natural conditions in recent decades has contributed to changes" (Storsletten and Jakobsen, 2013, p. 374), in the direction of an integrated union of spirit and matter.

One of the most serious weaknesses of the cultural creatives is that they often have weak networks indicating that they do not possess a good capability for working together and supporting one another. Hence, social isolation may pose a major problem in relation to realizing new ways of life in society. "Until they develop a substantial sense of community, their fledgling movements, businesses, and institutions cannot grow, and potential political leaders cannot create a common cause with them" (Ray and Anderson, 2000, p. 94). Lindner describes the importance of network:

We are a global transdisciplinary network and fellowship of concerned academics and practitioners. We wish to stimulate systemic change, globally and locally, to open space for dignity and mutual respect and esteem to take root and grow, thus ending humiliating practices and breaking cycles of humiliation throughout the world (Lindner, 2012, p. xxii).

\section{Methodology}

To develop information and knowledge relevant for the regional political planning processes it was important to design café dialogues suited for the creation of realistic ideas and visions, not focused on extreme pessimism or negativism. It was also crucial to refrain from aborting ideas through offering comments such as: "it can't be done" (Lindner, 2012, p. 144). Rather than asking who is right and who is wrong, it was important to inspire the participants to describe the interplay, as well as the complexity of the natural and social world. Self-reflection was needed on all sides, rather than 
one-sided contention that good intentions are sufficient, even if the desire to do good is of the utmost value - wherever it occurs.

To satisfy some of these premises our empirical material was collected through café-dialogues in which representatives from civil society, business organizations, local government, and NGOs participated. A prerequisite for any creative process is that the participants represent different perspectives and interests. The first idea behind café-dialogues is that people with different perspectives, in a communicative setting, will come up with creative questions and solutions. The second idea is that, by taking part in the dialogical processes, the participants will develop knowledge and awareness concerning their own norms and values. The third idea is that participants develop understanding of the other participants' perspectives and perception of reality.

We used two different methods to collect the information. First, we interpreted the notes, drawings, and comments made during the dialogues. In order to catch the spontaneity in the dialogues, the participants were encouraged to write and make drawings on the paper table cloth during the sessions and these notes were later transcribed and interpreted. Second, the participants filled in a questionnaire to evaluate the dialogical process.

The purpose of the café-dialogues was to stimulate people in different regions in Northern Norway, to describe their vision of ecologically and socially sustainable local societies in 2030, and to describe what has to be done to move in the right direction.

Before starting the dialogue, the participants were given four "inspiration" lectures, one with general perspectives on the future, one lecture by a local resource person, a lecture introducing a circulation economic perspective on the future, and an introduction to dialogue as work form. The café-dialogues were open for all inhabitants in local communities. The participants rotated between the three different questions at the three different tables. At each table a host facilitated the dialogue and wrote down the themes discussed and the conclusions. After the dialogues were finished the hosts summed up in a plenary session. Hence, the qualitative data from the café-dialogues consists of the participants writing on the table cloth, a summary, and a presentation given by the hosts as well as additional comments from the participants. Everything was transcribed before interpretation started.

At the end, the participants were asked to fill in a questionnaire. The questionnaire was completed by 144 of the 200 participants at the café-dialogues. Table I summarizes the reported opinions concerning the various questions. The table can be read as follows: the mean score on Question 1 (solutions based on circulative value chains) is 5.4 on a Likert scale from 1 to 7 . The result indicates that the participants think that circular value chains will be part of sustainable local societies in 2030.

\section{Interpretation of empirical findings}

Even if it is impossible to draw general conclusions from the empirical material, the interpretation of the data shows interesting results. First, the viability of local societies seems to depend on to what extent the municipalities succeed in their efforts to make use of local natural and human resources (q7, score 6.1). In addition viable societies are focused on qualitative values (q6, score 6.0). Value pluralism points in the same direction (q3, score 5.8). "Increased collaboration in the region" (q9, score 6.0) is also of great importance in order to develop sustainable societies which will be attractive for people in the future. The results from the questionnaire also indicate that the participants do have faith in local society's ability to resolve its own challenges.
Developing sustainable societies

589 
IJSE

42,6

590

Table I.

The importance of some factors leading to viable local societies
Questions

Mean

1. Solutions based on circulative value chains

5.4

2. Cooperation between stakeholders

5.7

3. Value pluralism

5.8

4. Bottom-up initiatives

5.7

5. More emphasis on collective goods than on private consumption 5.8

6. More emphasis on qualitative values than on quantitative values 6.0

7. More use of local resources and competence 6.1

8. Increase the population in the region $\quad 5.2$

9. Increase the collaboration in the region $\quad 6.0$

10. More emphasis on local small-scale solutions $\quad 5.6$

11. More emphasis on centralized solutions $\quad 3.7$

12. More emphasis on local solutions $\quad 5.7$

13. The café-dialogues gave me increased consciousness of my own position in network $\quad 4.9$

14. The café-dialogues gave me new thoughts and ideas 5.1

15. The café-dialogues established new relations 4.7

16. The café-dialogues with different people gave me new understanding 4.9

"Bottom-up initiatives" (q4) and "more emphasis on local solutions" (q12) both show a high score of 5.7. This assessment is strengthened by a very low score (3.7) on "more emphasis on centralized solutions" (q11).

The last four questions focus on the dialogical process and showed relatively low scores. Some of the participants indicated, on their table cloths, that the main reason was a general shortness of time. The general impression is that the participants liked café-dialogues as a method for developing new thoughts and ideas. But as just noted, several comments called attention to the fact that the dialogues were carried out too "fast". The participants felt that they had not had enough time to delve more deeply into the rather complex questions asked.

On the table cloths, we found arguments for increased focus in the advertisements to stimulate settlement, on plurality in the field of jobs and cultural activities, in addition to possibilities for different new outdoor activities in nature. On many table cloths we found scribbling saying that small local societies in the countryside, in order to be attractive, must have good public transport connections to the closest town centre in the region. This means high-quality public transport and a high standard of roads. The consequence of this would be that it is not then necessary to establish all types of service organizations in each small community.

We also found sentences indicating that more extensive cooperation between the business sector and culture is needed in the future. Several statements supported greener strategies: several participants particularly mentioned renewable energy, organic products, proximity, environment, and nature. People, local business, proximity and the living environment were mentioned by many participants. Others argued that the availability of good infrastructure helps promote good solid growth.

Several table cloths included expressions focusing on the need to develop jobs for both men and women. This means that it is important to stimulate diversified development including a great diversity of businesses, industries, and public sector workplaces. If families are to find it attractive to live in a small local community, the community must be adapted to the needs of the whole family, including the children. In addition many participants emphasized that it was necessary to provide diversified cultural activities. 


\section{Factor analysis}

To examine whether the statements reflect a set of underlying dimensions, we conducted an exploratory factor analysis. Factor analysis is rightly described as both an art and a science, one consequence is that it is not relevant to draw exact scientific conclusions from the empirical material. The reason for choosing factor analysis was the qualitative nature of our research process. Factor analysis could be described as a data-reduction technique because it reduces a large number of overlapping variables to a smaller set of factors that reflect the underlying dimensions of the data. We did not have a priori knowledge of how many categories that could be applied amongst the respondents. This approach allowed us to identify dimensions not directly observable, and then determine which dimensions the various variables reflect. In our analysis we applied varimax rotation, i.e. the extracted factors are ortigonal. This was mainly done to facilitate interpretation. The factor analysis extracted four components with factors loading $<0.50$. We ended up with four categories; two of them can be compared with the moderns, and two of them have similarities with the cultural creatives. There was no category aligned with the traditional.

\section{Entrepreneurs - Moderns 1}

This category of participants in the café-dialogue is characterized by being entrepreneurial, focused on change processes, but without a clear idea of the direction of the change. They think that networking, establishing new relations, new thoughts and ideas, are important means of building a society based on diversity. They do not reflect specifically on values and visions.

In the first component in the factor analysis the following factors load higher than 0.50; q13 "position in networks" (0.788), q14 "new thoughts and ideas" (0.716), q15 "new relations" (0.675), and q16 "new understanding" (0.813). This category first and foremost reflects creativity and it is labelled entrepreneurs; this group has similarities with the group Ray and Anderson (2000) call moderns.

People associated with this component are more focused on process than product. We cannot read in anything about how society would look like or which values are most important. The only thing we can conclude is that entrepreneurs look for novelty and processes that stimulate creativity. Entrepreneurs - Moderns 1 are characterized by statements saying that building networks are important for creating new jobs:

(1) networking (0.788);

(2) focus on new thoughts and ideas (0.716);

(3) establishing new relations (0.675); and

(4) new understanding (0.813).

At some of the cafe tables the participants argued that viable local communities in the future depend on how immigrants were integrated in local networks, both socially and economically. They argued that the possibilities to live a good life were coupled to the success of developing positive attitudes towards multicultural integration.

All these characteristics are in accordance with Ray and Anderson's description of moderns as positive to freedom concerning gender, and ethnicity, and new technologies and urbanization.
Developing

sustainable

societies

591 
IJSE

42,6

592
Growth and control-Moderns 2

This component group differs slightly from Moderns 1 . Their ideas about the future are based on growth, both in terms of the economy and the population. They want to build strong regions based on centralized solutions, growth and control.

The following factors; q8 "increase population" (0.758), q9 "collaboration in the region" (0.620), and q11 "centralized solutions" (0.669), load onto the fourth component. We label this factor "Growth and control". Growth and control - Moderns 2 is as follows:

(1) growth in population (0.758);

(2) regional cooperation (0.620); and

(3) centralized solutions (0.669).

In this category we find people who believe in solutions based on growth and centralized initiatives. They ask for bigger highways and increased population. The growth ideology is illustrated by statements such as we want " 35,000 inhabitants [in 2030] versus 20,000 (today)", and one of the local speakers welcomed a development making the city the largest logistical point in Northern Europe. The ideas behind such development are rooted in mainstream economy's vision of exponential growth. It is worth noting that we only found statements clearly belonging to this group on one table cloth. This indicates that this group is small compared to the others. According to Ray and Anderson, powerful technologies, nation-states and large corporations are part of modernism.

\section{Circulation economics - Cultural Creatives 1}

This category consists of people presenting ideas for a sustainable society based on circular value chains, pluralistic value systems, cooperation as opposed to competition, bottom-up solutions and focus on collective goods. The people in this category have a perspective of the future exceeding the local level and emphasize the importance of building national and international networks. The practical solutions need to integrate ecological, societal, and economic values.

The below list shows the most clear-cut component in the matrix. When reading down the column for this category, we observe that q1 "circulative value chains" (0.575), loads onto this factor. Furthermore we observe that q2 "cooperation" (0.700), q3 "value pluralism" (0.615), q4 "bottom-up initiatives" (0.700), and q5 "collective goods" (0.537). The category reflects the position of cooperation within decentralized circular values chains. We label this factor "Circulation economics - Cultural Creatives 1":

(1) circular value chains (0.575);

(2) cooperation between stakeholders (0.700);

(3) value pluralism (0.615);

(4) bottom-up solutions (0.700); and

(5) collective goods (0.537).

Many of the participants emphasized the need to create communicative arenas in which every actor can be integrated in a comprehensive network. Integrating youth and immigrants are of special importance. To develop viable societies in the future competence from local inhabitants must be mixed with the immigrant's skills and knowledge. Since migration within the region is also of great importance, the 
integration of immigrants must not be at the expense of the local inhabitants. This way of thinking resembles the vision of circulation economics (Ingebrigtsen and Jakobsen, 2007).

Circulation economics has developed from ecological economics; a goal is to find out how one should act in order to: "achieve the highest possible degree of effective use of natural resources for the purpose of fulfilling human needs, whilst at the same time respecting the characteristics and inherent values of culture and nature" (Ingebrigtsen and Jakobsen, 2007, p. 109). Circulation economics is based on an eco-development perspective; environmental and sustainability problems and issues can only be solved if the economy is subordinated to ecological principles. The goal of economy must be a contribution to life quality, and not economic growth for the sake of growth (Ingebrigtsen and Jakobsen, 2006).

Statements written on paper table cloths stating that it must be possible to live in one local community and work in another, stress the need for better infrastructure and communication. This was an argument for asserting that it was unnecessary to have all types of service provision everywhere. Cooperation is also strengthened by sentences indicating that we need a viable centre, but also a viable region in the environs. We also found statements declaring that people must contribute in a viable society; the authorities cannot just fix everything. Increased participation also contributes to individual satisfaction and well-being. To be an active part of changing processes gives people meaning. According to Ray and Anderson, the cultural creatives have a positive vision of the future and they are concerned about the condition of the planet and the well-being of people. The perspective of cultural creatives is holistic and process oriented.

\section{Small is beautiful - Cultural Creatives 2}

Small is beautiful - Cultural Creatives 2 - is populated by persons characterized by ideas and visions for a future society based on qualitative values, local resources and competence, small-scale solutions, and local initiatives. The people belonging to this category focus on small local communities and prefer using local resources on site.

In the last component we see that q6 "qualitative values" (0.502), q7 "local resources" (0.649), q10 "small scale" (0.777) and q12 "local solutions" (0.667) loads higher 0.50 . We label this factor "Small is beautiful":

(1) qualitative values (0.502);

(2) local resources and competence (0.649);

(3) small-scale solutions (0.777); and

(4) local solutions (0.667).

People loading on the component named Cultural Creatives 2 are focused on their own local community. They wish to make use of local resources and prefer therefore smallscale production. They concentrate on local initiatives, and qualitative values fit the interpretation of a group of people trying to build their own society. Statements we associate with this position are, e.g. "it is easier to think big thoughts in small societies" and "the consumer culture needs to change". Some participants pointed to the need for increased production and consumption of local food, "choose local food". This category in many ways resembles the image of man built on Schumacher's (1973) vision "Small is Beautiful"; here he draws the attention to alternative ways of organizing society based on small scale and intermediate technology and use of local and resources
Developing sustainable societies 
IJSE

42,6

594

locally. We can sum up this using a sentence from one of the local speakers: "The path to a viable society is found by using the local initiative rooted in the culture to use the local resources in the best way".

\section{Discussion}

Based on the words, sentences and drawings on the paper table cloths, along with the results from the questionnaire, the factor analysis and the theoretical context, we can derive some interesting conclusions relevant for the political planning process in Nordland. The interpretation of the results indicates that it is necessary to take steps away from the mainstream economic model based on centralization and economic growth to a path based on collaboration between stakeholders in a local and regional perspective.

Even if the findings do not give exact answers regarding how many of the participants in the café dialogues belong to the different categories, we do have enough knowledge to conclude that; growth, bigger units and the constant craving for greater consumption do not have a dominant position in the region. The participants' awareness of the importance of living their lives integrated in well-functioning societies in harmony with nature's ecosystems is interesting. The results indicate that in all regions the participants described a greener future characterized by less transport and more cooperation aiming at more ecologically sound production, distribution, consumption, and redistribution.

Our findings are in accordance with research in management theory which is moving away from focusing on the characteristics of leaders as persons, to studying the relationships between managers and employees and other stakeholders who managers have relationships with (Storsletten and Jakobsen, 2013). This approach has turned out useful in order to explain many real-world phenomena. Network theory provides less scope for individual agency and the ability for individuals to influence their own success. The reason for this is that much of it rests within the structure stating that network theory focuses on relationships and discusses how and why they are established, and what the various relationships represent. Network theory can also indicate how different relationships affect behavior, and how relationships grow, and decay over time.

Our extraction of four components, based on factor analysis, indicates that the participants in the café-dialogues had different opinions about how to move from today's situation to the society of the future. The participants loading under the component "Circulation economics - Culural Creatives 1 " were characterized by a perspective exceeding the local level and stressing the importance of different values. Of special importance is the focus on bottom-up initiatives to integrate different industries, distribution channels, consumers, and reprocessing industry in circular value chains. The practical solutions following from this component point to an idea of integrating ecological, societal and economic values in practical politics. Amongst the participants loading under the component; "Small is beautiful - Cultural Creatives 2", we find people focused on the qualitative development of their own small communities based on local natural and human resources. They differ from circulation economists along several dimensions. First of all, they give priority to qualitative values and small-scale local solutions. Participants loading under the component; "Entrepreneurs Moderns 1" load on factors such as networking, novelty, and creativity. The common denominator is process, not product. They search for new solutions without too much focus on underlying values and ideas. Hence, it is not easy to interpret the entrepreneurs along the same dimensions as the other components because we only have indirect 
information indicating local focus and qualitative values. Growth and control - Moderns 2 focus on growth in the population and centralized solutions. They want to build strong regions based on quantitative growth. They think that centralized solutions are the best guarantee for developing small communities in district areas.

\section{Conclusion and political implications}

It is interesting to notice that many of the ideas presented in the café dialogues are found in the Regional Plan for Nordland (2013-2025). The report focuses on three target areas:

(1) quality of life;

(2) livable communities and regions; and

(3) value creation and skills.

In accordance with the results reported and interpreted from the café dialogues, the politicians describe the three target areas along a wide range of disciplines, sectors, interests, and opportunities. In the Regional Plan for Nordland concrete goals are connected to each target. In addition, strategies and measures are described in detail. Most strategies and initiatives have a wide range and contribute to development in more than one target area. It seems clear that inspiration from ideas characterizing the cultural creatives have a substantial influence on the political planning process in Nordland County.

Nordland County faces these challenges in the following way. The goals for the development i Nordland is described in RPN; "Sustainable management must be based on a balance between social development, economic development within the context of the natural and cultural environment [...] An environmentally responsible use of the North's resources is a prerequisite for sustainable economic development and improved quality of life for the people of Nordland” (Regional Plan for Nordland, 2013-2025, p. 4).

\section{References}

Berry, T. (2007a), "Teilard in the ecological age", in Fabel, A. and John, D. St (Eds), Teilard in the 21st Century, The Emerging Spirit of Earth, Orbis Books, New York, NY, pp. 57-77.

Berry, T. (2007b), "The new story - comments on the origin, identification, and the transformation of values", in Fabel, A. and John, D. St (Eds), Teilard in the 21st Century, The Emerging Spirit of Earth, Orbis Books, New York, NY, pp. 77-89.

Eisenstein, C. (2011), Sacred Economics - Money, Gift \& Society in the Age of Transition, Evolver Editions, Berkley, CA.

Ims, K. and Jakobsen, O. (2008), "Consumerism and frugality; contradictory principles in economics", in Bouckaert, L., Opdebeeck, H. and Zsolnai, L. (Eds), Frugality - Rebalancing Material and Spiritual Values in Economic Life, Peter Lang, Oxford, pp. 169-184.

Ingebrigtsen, S. and Jakobsen, O. (2006), "Circulation economics - a turn towards sustainability", International Journal of Social Economics, Vol. 33 No. 8, pp. 580-593.

Ingebrigtsen, S. and Jakobsen, O. (2007), Circulation Economics, Peter Lang publ, Oxford.

Ingebrigtsen, S. and Jakobsen, O. (2009), "Moral development of the economic actor", Ecological Economics, Vol. 68 No. 11, pp. 2777-2784.

Lindner, E. (2012), A Dignity Economy - Creating an Economy that Serves Human Dignity and Preserves Our Planet, Dignity Press, Lake Oswegfo, OR. 
IJSE

42,6

596

Max-Neef, M. (2010), "The world on a collision course and the need for a new economy",Journal of the Human Environment, Vol. 39 No. 3, pp. 200-210.

Merton, R.K. (1936), “The unanticipated consequences of purposive social action”, American Sociological Review, Vol. 1 No. 6, pp. 894-904.

Ray, P.H. and Anderson, S.R. (2000), The Cultural Creatives, Three Rivers Press, New York, NY.

Rees, W. (2007), "Sustainable development and the ecosphere - concepts and principles", in Fabel, A. and John, D. St (Eds), Teilard in the 21st Century, The Emerging Spirit of Earth, Orbis Books, New York, NY, pp. 103-127.

Regional Plan for Nordland County (2013-2025), Norway (RPN), Nordland County.

Regional Plan strategy for Nordland County (2012-2016), The Knowledge Foundation, (RPSK) Regional Plan Strategy for Nordland County, Nordland County, available at: http:// rkknordland.no/fylkeplan-for-nordland-2013.pdf

Schumacher, E.F. (1973), Small is Beautiful. A Study of Economics as if People Mattered, Vintage, London.

Storsletten, V.M.L. and Jakobsen, O. (2013), "Revolution and evolution in economics, business management and leadership theory", in Midttun, A. (Ed.), CSR and Beyond, Cappelen Damm Akademisk, Oslo, pp. 365-386.

Taylor, C. (1991), The Ethics of Authenticity, Harvard University Press, London.

Whitehead, A.N. (1978), "Process and reality", in Ray Griffin, D. and Sherburne, D.W. (Eds), Corrected Edition, The Free Press, New York, NY.

Zsolnai, L. (2011), "Environmental ethics for business sustainability", International Journal of Social Economics, Vol. 38 No. 11, pp. 892-899.

\section{Corresponding author}

Dr Ove Jakobsen can be contacted at: ove.jakobsen@uin.no

For instructions on how to order reprints of this article, please visit our website:

www.emeraldgrouppublishing.com/licensing/reprints.htm

Or contact us for further details: permissions@emeraldinsight.com 